\title{
Discussion of Building a Tourist Information Service Platform Based on Cloud Computing
}

\author{
Lianying Sun \\ College of information technology, \\ Beijing Union University \\ Beijing, China \\ e-mail: sunlychina@buu.edu.cn \\ Tao Peng \\ College of information technology \\ Beijing Union University \\ Beijing, China \\ e-mail: pengtao@buu.edu.cn
}

\author{
Chang Liu* \\ College of information technology \\ Beijing Union University \\ Beijing, China \\ e-mail: xxtliuchang@buu.edu.cn \\ Qixiu Zhang \\ College of information technology, \\ Beijing Union University \\ e-mail: hack_ok_25@qq.com
}

\begin{abstract}
With the development of tourism and the Updating of modern service concept, the quality and convenience of information services was paid more and more attention. It is necessary to building diversity, three-dimensional network platform for public Travel Services Platform in order to enhance Tourism service capabilities. After analyzing the characteristics of tourism information resources and demand, travel services model is discussed on the basis of cloud computing technology, the system architecture, key technology and means of developing is Investigated, so that provide technical support for building cloud travel service platform.
\end{abstract}

Keywords-cloud computing model; saas; travel services component

\section{INTRODUCTION}

With the development of the tourism industry continuously and the emerging of a variety of smart phones constantly, computers and other mobile terminals supported by the technology of cloud computing and networking, it become a possibility to get the information you need by fingertips. Tourist information is complicated extensively, including direct description of tourist activity information (including tourist information, tourist destination information, travel service agency information, etc.) and travel activities are closely linked to indirect information (such as political, economic, cultural, legal, technological environment, etc.), and has comprehensive, sensitive, timeliness, development and non-definitive characteristics that have a significant impact on tourism activities [1]. With the development of computer networks, all people have changed the way of access to information, most of the tourists search the tourist information from the traditional media organizations turned to the channels of communication through the network to collect information, such as the forum, blog, micro-blog, so performance of machine and ability of software must be provided, some customs have difficult to obtain the service freely. Cloud computing technology joined a huge systems and resources together, changed the service mode, with the advantages of a very large scale, visualization, high reliability, versatility, highly scalable, on-demand service, easy use, etc., which can be used to build public platform travel services.

The cloud travel services technology model, system design and implementation method for the construction of diversified, three-dimensional, networked public travel service platform are discussed in the paper, which will provide technical support to share information resources, improve the level of modern service.

\section{ANALYSIS OF SERVICES}

As we known, different groups have different target in the trip. Some concern landscape, anther concern geography and religious. How to make them obtain the information that they are eager for become a problem eager to be solved. Cloud travel service platform need to provide information services with the characteristics of popular, comprehensive, behavioral, feature and so on, so classified information of service is discussed firstly.

\section{A. Service Object Analysis}

Service platform service for four categories of users mainly, the first category are a registered user, with the features of long-term service; The second is the casual user, that need to get topical information, with the features of temporary, targeted strong; The third category user are mobility customers which visit in a tourist area, with temporal and spatial characteristics, they are need to provide emergency services. The fourth category is travel suppliers, travel suppliers, travel agencies or travel companies such as hotels, scenic spots. Cloud services platform service user objects and key service requirements shown in Fig. 1. 


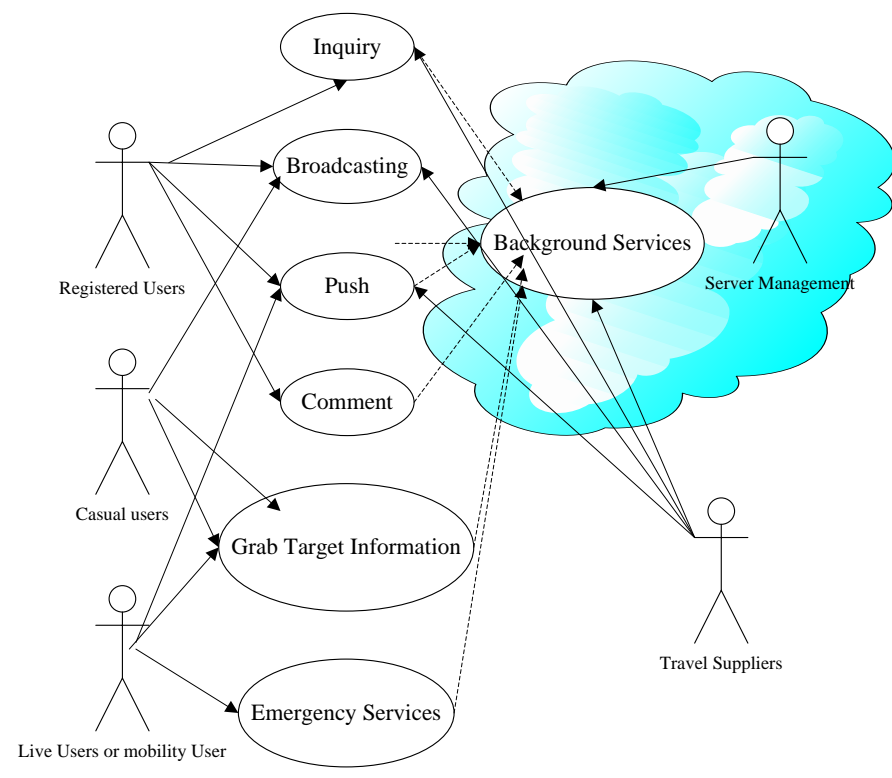

Figure 1. User objects and key service requirements of cloud services platform service

\section{B. Introduction Of Main Services}

\section{1) Information inquiry}

Information inquiry is shown by two forms in this system, one type information is classified according to attractions characteristics, another is searched by location map, classified information inquiry is shown in details as Fig. 2.

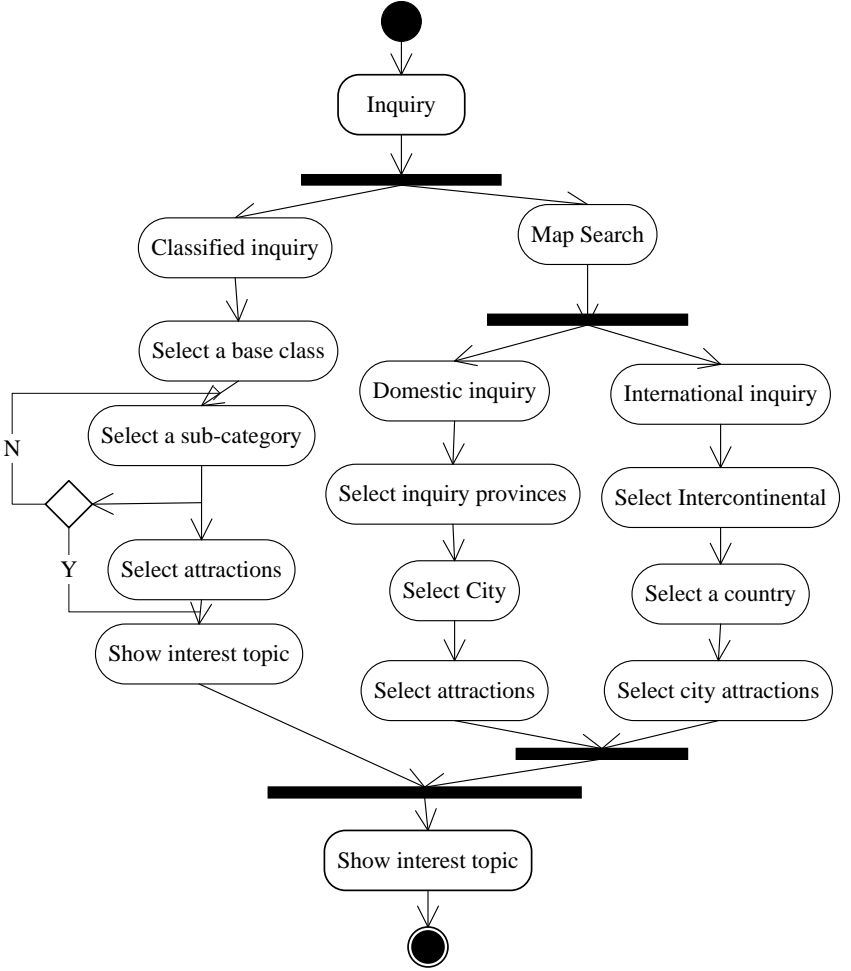

Figure 2. Classified information inquiry
Attractions Classified inquiry first select the basic classification: natural, cultural, religious, urban civilization. When the user determines that the base class, the system will be a detailed list of categories attractions. If you select a detailed list of categories of natural, mountains, valleys, forests, grasslands, deserts, caves, lakes, rivers, streams, springs lake, hot springs, waterfalls, etc. Vill be shown, Similarly, a detailed list of categories humanities include: site, residence, folklore, ancient, ancient architecture, towns, houses, arches, castles, ruins ruins, ancestral halls, palaces, tombs, monument towers, pavilions, etc.; religious detailed list of categories, including: Islam, Buddhism, Indian Buddhism, thirteen, Tibetan Buddhist / Lamaism, Taoism, Confucianism, Christianity, the Roman Catholic / Catholicism, Orthodoxy / Orthodox, Protestant / Christian / Protestant; Choose from the detailed list of categories, you can enter information interface that you're interested in.

Map search display information in the form of maps. The information classed by region, the user first selects the domestic information query or abroad information inquiries by clicking on the map. If you choose the international information query, the interface will appear with a world map, then the user clicks to query Intercontinental (including Asia, North America, South America, Africa, Europe, Oceania, Antarctica), and then select the country you want to query, system interface will display the country's famous attractions, click on these attractions can view the attractions in details.

2) Broadcast and push

Currently many tourist products message spread by more use of paper flyers, newspaper or SMS with higher costs, greater consumption. Our products are designed based on mobile Internet network, travel suppliers to provide customers with information by mobile push service, and includes:

- Living broadcasts. The brief text description of promotional activities are send to all APP users.

- Delay regional push. When users enter a attractions nearby area, will receive more latest promotional information by technology of location-based push driven.

The system design is C / S mode based on the idea of mobile Internet. Server-side includes data server and push server, data server is responsible for data registration and data storage, push server is responsible for pushing the message. Android platform mobile client side is chosen to be in charge of receiving and displaying messages. Registered on the server data, tourism services providers input the information which will be pushed, and then the push server push information to the customer phone. Push process: Travel Service Provider $\rightarrow>$ Data Servers -> push server -> client -> data server (for push details).

\section{3) Topic information searching}

As the development of mobile Internet and Web technology continually, mobile Internet (for example microblog, etc.) gradually become an basic tools of communication and entertainment everyday. To the end of December 2012, Sina micro-blog had more than 500 million 
registered users, 46.29 million daily active users, 75 percent of daily active users from the mobile client. It is very large amount of data and information (such as news, forums, blog, micro-blog, social networking sites) collected from the mobile Internet. But how to effectively solve the "pieces of information" and "information overload", "spam content" and other issues has become a challenge. People are creating data on the internet while also browsing data, Therefore, the ultimate goal of tourism services is to provide users with location-based and user interest-based personalized recommendation by mining the user's interest and needs, clustering behavior characteristics. Meanwhile, the government, enterprise information can be pushed to users in the most efficient way to make users receive the hot topic information with timeliness, authenticity and higher propagation. It has higher political significance and social and cultural significance to provide users with faster, more efficient service.

A multi-level, multi-dimensional search model is designed by way of analyses the open API and traditional way of web crawlers comparatively in the process of system design.

\section{4) Emergency Services}

Emergency services includes three cases

The first is the traveler eager to learn how to reach the destination or achieve a particular purpose, such as how to ride, how to go to the hospital, how to find the ideal hotel, etc., at this moment his most needed services is to obtain objective information by use of handy tools such as mobile phones and other mobile devices, with the characters of specific needs and rapid response.

The second is how to acquire and release the warning information. Timely warning information is published in accordance with authority, which includes: early warning level, the incident area or place, time of the incident, impact assessment and response measures. The information is released or adjusted through radio, communications, information networks or other means, for special people, special places the targeted push inform ways should be taken individually.

The third is information release and comments the tourist can release accident information and comments by the public travel service platform. The accident information includes: event information sources, time of the incident, the site of the incident, the scope of the nature of the incident, the incident momentum, tourists casualties and missing people and so on. Comments containing the user's understanding of attractions, real-life experience, user information collected archive by topic searching.

\section{Model Of Travel SERvices Based On Cloud COMPUTING}

"Cloud tourism" is a travel service mode based on cloud computing technology, with non-download, non-installation, non-upgrade hardware. You not only through the cloud server obtain the instant travel service, but also read the same tourist information by multi-terminal, which get rid of the hardware device control. With the living standards and quality of life improved, the capabilities of modern tourism services is growing up, how to improve the quality of service and emergency service capabilities has become a hot research many experts and scholars. It is become a necessity to integrate multi-level, multi-faceted tourism resources. The cloud computing technology has changed the service mode, improved the level of tourism services, which achieved the sharing of information resources. A huge systems and resources are connected together by cloud computing technology. Through Internet technology the extended elastic IT-related capabilities is provided customers as a service.

Users only need to make use of relevant cloud services, no longer need to purchase expensive hardware investments, to overburden the frequent maintenance and upgrades. They can enjoy a variety of cloud services provide travel services, just to use a terminal to access the network. The infrastructure of public cloud tourism service model shown in Fig. 3.

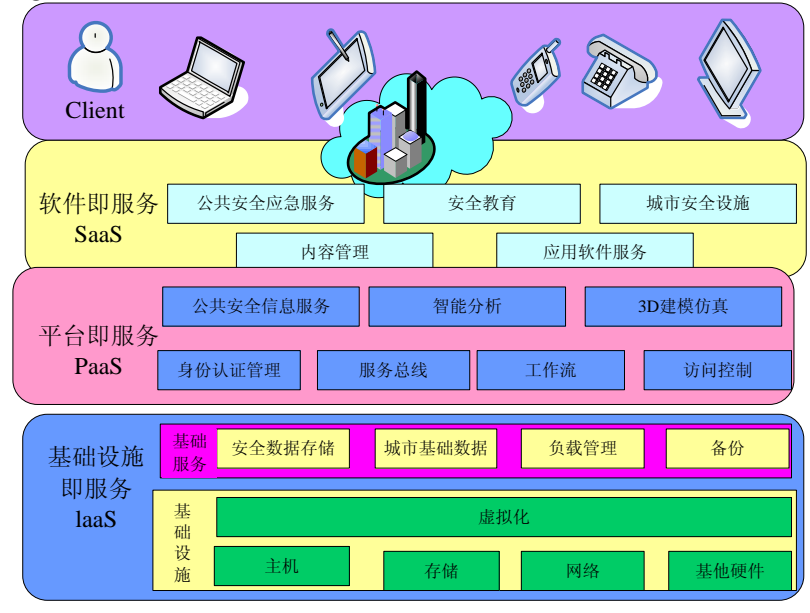

Figure 3. The infrastructure of public cloud tourism service model

According to the characteristics of tourism services, the cloud travel services model is designed corresponding to the classic architecture of cloud computing. SaaS layer does not require users to install software on their computers or servers, get its own needed, with the corresponding software-enabled services through a service level agreement (SLA) directly. Customers do not need to purchase hardware and software, can create, test, and deploy applications and services only by use of the PaaS platform. The IaaS layer provides users with computing resources remotely, including computers, storage, and related functions provided by the network. But they do not need to support the computing power of the IT hardware and software to pay the corresponding original investment cost.

\section{DESIGN AND PRACTICE}

In order to cloud travel platform used by different customer groups anywhere, this system take the combined mode of $\mathrm{B} / \mathrm{S}$ and $\mathrm{C} / \mathrm{S}$. 


\section{A. User Information Acquisition}

The user information is recorded through complete user registration, select individual registration, groups registered or travel provider to enter the registration interface, fill in the information submitted to complete the registration.

As an example, group information registration interface include group name, basic information of the group head, group size. User must fill out the information and submit it, and then the registration is completed.

\section{B. Developing The Searching Functions}

Users input the name of the interesting attractions interested in the search box, the system will find attractions according to user input information and find matches returned to the user, the user clicks to search for points of interest, they can enter into the attraction Attractions Introduction interface to view the corresponding information on attractions, it is shown as Fig. 4.

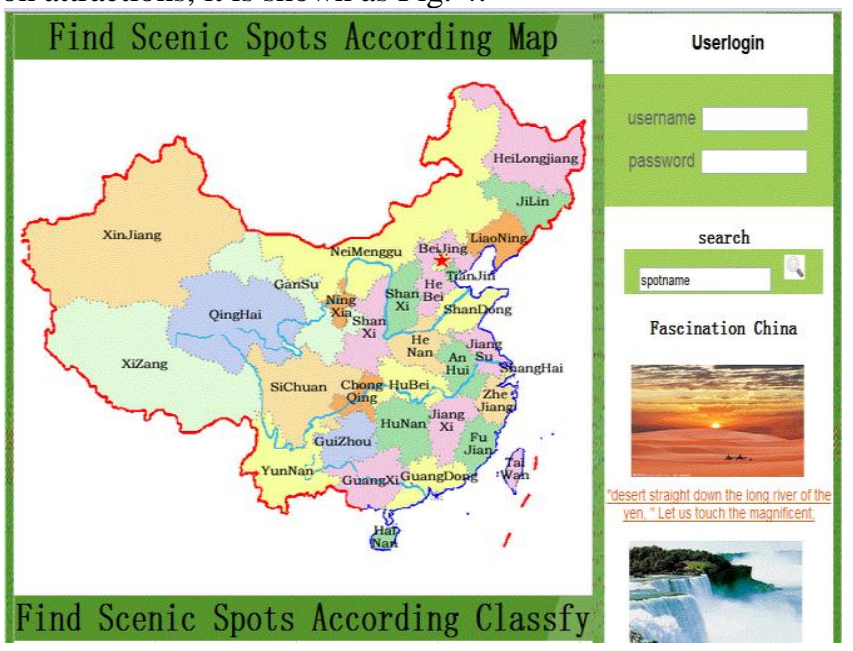

Figure 4. Attractions information inquiry

After selected the topic attractions information, the system will appear the interface corresponding attractions. Including traffic information, accommodation information, gourmet specialty information, customs information, weather information, attractions profile, price information, user's evaluating information.

\section{Comments And Emergency Service}

Evaluation function includes your friends to check all the attractions evaluation.

If you are a backpacker, then click on the interface looking for backpackers, input arrival date of the attractions, you can see all the attractions the date of backpackers and contact information, so that you can have companions easily.

$$
\text { CloudeTranvel colums }
$$

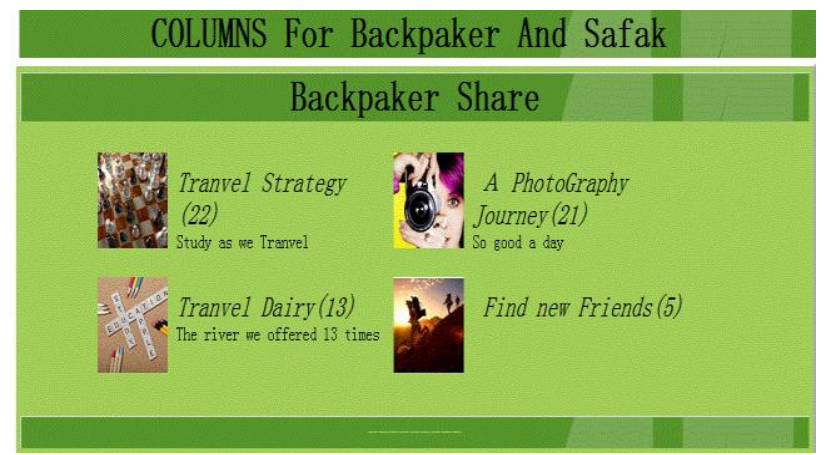

Figure 5. Comments and emergency service

\section{CONCLUSION}

Studied in the key technologies to construct the tourist cloud public services platform is a hot problem, which can solve how to share information resources, construct information classification push model, Software development techniques and other issues. Practice shows that the cloud service mode of travel services such as user behavior analysis, themes grab and push, emergency services and other functions has a practical value for the urban public travel service platform, and provide technical support for the tourism cloud.

\section{ACKNOWLEDGMENT}

We thank all program and local committee members, and volunteers for their hard work and contributions to the ICSECS conference. This work is partially supported by Funding Project of National Science Foundation of China (NSFC, 40672104), Talents Support Project of Talents Enhancing University Development Plan in Beijing Union University(BPHR2011A04, BPHR2012F01). And thank all of experts and scholars referenced in my paper, and all of devoting to this study.

\section{REFERENCES}

[1] Wei Yu, Docking of Slow Travel and Tourism cloud - a new semiportability travel packages, and Model Construction,Chinese foreign investment, 2011, 16

[2] Chen Kang, Zheng Weimin, cloud computing: system instances and Research, Journal of Software, 2009,Vol.20 (5),pp.1337-1348

[3] CHEN Quan, DENG Qianni, cloud computing and its key technologies, Computer Applications, 2009,Vol.29 (9),pp.2562-2567

[4] Qinliang Juan. Tourism Tourism cloud era public information services . Tourism Tribune, 2012,Vol.27 (2)pp. 9-10

[5] ZhouXiangbing,MAHongjiang(etc.)AnArchitectureApproachofTouris mCloudBasedonCloudComputing,JournalofChongqingNormalUniver sity(NaturalScience,2013,Vol.30 No.2,pp.79-86

[6] Sun Lianying Liu Chang.Investigate of Urban Safety Service Model based on Cloud Computing,Computer Science,2011,vol.38(10),pp.8991 